Société d'histoire de la révolution de 1848 et des

révolutions du XIXe siècle

$46 \mid 2013$

L'espace du politique en Allemagne au XIX' ${ }^{\mathrm{e}}$ siècle

Anne M. Butler, Across God's Frontiers. Catholic Sisters in the American West, 1850-1920

Chapel Hill (N.C.), The University of North Carolina Press, 2012, 424 p. ISBN: 978-0-8078-3564-4. 45 dollars.

Tangi Villerbu

\title{
CpenEdition
}

Édition électronique

URL : http://journals.openedition.org/rh19/4509

DOI : $10.4000 /$ rh 19.4509

ISSN : $1777-5329$

Éditeur

La Société de 1848

Édition imprimée

Date de publication : 1 juin 2013

Pagination : 228-230

ISSN : 1265-1354

Référence électronique

Tangi Villerbu, «Anne M. Butler, Across God's Frontiers. Catholic Sisters in the American West, 1850-1920

», Revue d'histoire du XIXe siècle [En ligne], 46 | 2013, mis en ligne le 13 janvier 2014, consulté le 22 septembre 2020. URL : http://journals.openedition.org/rh19/4509; DOI : https://doi.org/10.4000/ rh19.4509

Ce document a été généré automatiquement le 22 septembre 2020

Tous droits réservés 


\section{Anne M. Butler, Across God's Frontiers. Catholic Sisters in the American West, 1850-1920}

Chapel Hill (N.C.), The University of North Carolina Press, 2012, 424 p. ISBN: 978-0-8078-3564-4. 45 dollars.

\section{Tangi Villerbu}

\section{RÉFÉRENCE}

Anne M. Butler, Across God's Frontiers. Catholic Sisters in the American West, 1850-1920,

Chapel Hill (N.C.), The University of North Carolina Press, 2012, 424 p. ISBN:

978-0-8078-3564-4. 45 dollars.

1 Cela faisait longtemps que la somme d'Anne Butler était attendue. L'auteur avait déjà délivré ses réflexions sur le sujet dans diverses publications ${ }^{1}$ et il ne manquait plus que cet ouvrage pour couronner de longues années de recherche dans de nombreux dépôts d'archives de congrégations à travers les États-Unis. L'histoire des congrégations féminines du $\mathrm{XIX}^{\mathrm{e}}$ et $\mathrm{du}$ premier $\mathrm{xx}^{\mathrm{e}}$ siècle est devenue depuis une dizaine d'années un champ dynamique de l'historiographie américaine, qui a permis de moderniser quelque peu l'histoire catholique en y introduisant la notion de genre ou en la rattachant à l'histoire des politiques sociales, en découvrant finalement aux États-Unis ce que Claude Langlois - qui demeure parfaitement inconnu des historiens des États-Unis avait mis au jour pour la France en $1984^{2}$.

2 Ce refus du comparatisme mène d'ailleurs à une forme ancienne d'exceptionnalisme chez Anne Butler : si elle dit bien qu'être sœur au XIX pouvait être une forme de liberté, de promotion féminine, elle affirme qu'il s'agit là d'une différence radicale avec une vieille Europe engoncée dans des traditions médiévales, et donc d'un effet naturel de l'Amérique et plus encore de l'Ouest. Le propos est évidemment contestable, comme l'est le refus de lier des analyses quantitatives (on ne sait jamais combien furent les 
sœurs dans l'Ouest et aucune carte ne vient appuyer l'analyse de leur implantation) à une narration par ailleurs brillante.

3 L'étude se déploie thématiquement, hormis un ultime chapitre qui revient sur les évolutions du début du $\mathrm{xx}^{\mathrm{e}}$ siècle. Le choix des années 1850 comme début de cette histoire n'est pas réellement justifié et empêche Anne Butler de s'appuyer sur les excellents travaux de Sarah Curtis $^{3}$, sans que cela n'atténue la richesse du propos. Après une brève analyse des origines européennes des congrégations et de leur voyage vers l'Ouest, découverte difficile d'un environnement naturel et humain d'une radicale étrangeté, l'auteur décrit les tâches quotidiennes des sœurs. Leur travail : il s'agissait classiquement d'ouvrir des écoles et des hôpitaux, mais aussi, étant donné le contexte, de pourvoir à ses propres besoins et de s'éloigner physiquement, parfois seule, du couvent, ce qui déstabilisait des pratiques bien ancrées. Il manque parfois à l'analyse le facteur religieux : ainsi on peut douter que l'école industrielle ouverte à Saint-Louis par les Sœurs de la Miséricorde n'ait été qu'un lieu d'épanouissement social et professionnel et que les sœurs n'y aient été que des pionnières du travail social ( $p$. 100-102), car, enfin, il y eut bien un objectif religieux à ces fondations, un monde chrétien idéal à construire qui n'est pas évoqué ici.

4 Anne Butler s'engage avec bonheur dans une étude administrative des couvents. Et d'abord de leur financement car ni les diocèses qui demandaient leur présence ni Rome ne leur versaient d'argent; il fallait se débrouiller en faisant appel aux dons - ceux des paroissiens comme ceux venus d'Europe par l'intermédiaire des sociétés de soutien aux œuvres missionnaires-, et en s'appuyant sur la fortune personnelle des sœurs (Katharine Drexel en est le meilleur exemple), ou encore en vendant des services tels que les cours de musique. On peut regretter qu'aucune donnée chiffrée ne soit avancée, alors que subsistent çà et là dans les fonds d'archives des registres financiers d'établissements congréganistes. Ce sont ensuite les querelles quant au contrôle des sœurs qui sont scrutées: d'une part entre les évêques et les supérieures, d'autre part entre les supérieures et des sœurs souvent isolées loin de leur maison mère; dans ce cadre spécifique, des scissions ont eu lieu, du fait des occasions offertes d'accroître son pouvoir personnel et local.

5 Le chapitre le plus fascinant est sans doute celui qui concerne les opérations des sœurs en direction de trois groupes ethniques particuliers : Hispaniques, Africains-Américains et Indiens. Dans ce dernier cas, Anne Butler insiste à juste titre sur le pouvoir des Indiens eux-mêmes : ce sont eux qui appellent les sœurs (comme ils appellent souvent les prêtres), ce sont eux qui définissent les modes d'action des missionnaires en fonction de leurs intérêts propres et, in fine, une mission ne peut réussir que si les Indiens le souhaitent et à leurs conditions, notamment parce qu'elle doit correspondre à leur propre quête spirituelle et à leur manière d'agir en contexte colonial. De ce fait, les sœurs «avaient comme objectif d'implanter la foi mais la foi les environnait; de transformer les populations, mais les populations les transformaient» (p. 266). Cette transformation devait mener à une américanisation des sœurs, qui passa, dans les premières décennies $d u x^{e}$ siècle, par une professionnalisation de leurs tâches et une adaptation des traditions européennes.

6 Cette conclusion pose en fait question, et renvoie à un postulat qui court tout le long du livre: il y aurait une spécificité profonde du travail des sœurs dans l'Ouest. Il est difficile de partager ce point de vue car jamais Anne Butler ne compare ses religieuses avec leurs consœurs européennes du Xix ${ }^{e}$ siècle. En outre, il semble que son affirmation 
selon laquelle les sœurs ont bien cherché à préserver les traditions de l'Église tout en s'écartant des voies du passé peut s'appliquer hors de l'Ouest. Pour confirmer ou infirmer le propos, il faudra prolonger les analyses, et c'est en ce sens que cet ouvrage est bien majeur : il pose de nouvelles questions à l'histoire de l'Ouest et du catholicisme américain, et il est nécessaire, après cet essai de synthèse, d'approfondir le travail par des études de cas qui font cruellement défaut et qui s'appuieraient sur les sources les plus variées possibles, en Europe comme aux États-Unis.

\section{NOTES}

1. Cf. notamment: Anne M. Butler, 'Mission in the Mountains: The Daughters of Charity in Virginia City', in Ronald M. James and C. Elizabeth Raymond (eds), Comstock Women: The Making of a Mining Community, Reno (Nev.), University of Nevada Press, 1998; Anne M. Butler, 'Pioneer Sisters in a Catholic Melting Pot: Juggling Identity in the Pacific Northwest', American Catholic Studies, $n^{\circ}$ 114/1, 2003, p. 21-39; Anne M. Butler, “'We had no assistance from anyone - Happier to do it alone": Montana, the Missions and Mother Amedeus', in Dee Garceau-Hagen (ed.), Portraits of Women of the American West, New York, Routledge, 2005, p. 91-121; Anne M. Butler, 'There are Exceptions to Every Rule: Adjusting the Boundaries - Catholic Sisters and the American West', American Catholic Studies, $\mathrm{n}^{\circ}$ 116/3, 2005, p. 1-22.

2. Claude Langlois, Le catholicisme au féminin: les congrégations françaises à supérieure générale au XIX siècle, Paris, Le Cerf, 1984.

3. Sarah A. Curtis, Civilizing Habits : Women Missionaries and the Revival of French Empire, New York, Oxford University Press, 2010 et Sarah A. Curtis, "Traverser les frontières: Philippine Duchesne et les Sœurs du Sacré-Coeur dans le Missouri des années 1820 aux années 1840 ", Histoire \& Missions Chrétiennes, $n^{\circ}$ 17, mars 2011, p. 59-82. 